\title{
The nexus of energy and water in China
}

\author{
Ding $\mathrm{MA}^{1, a}$ \\ ${ }^{1}$ State Grid Energy Research Institute, Beijing 102209, China \\ amartin8725@126.com
}

Keywords: China, Energy and water nexus, Water fee, Power sector

Abstract. Energy and water are inextricably linked. The limited endowments, uneven temporal and spatial distribution, and low utilization efficiency of energy and water pose great challenges to China's sustainable development. In this paper, a bottom-up model (CEMES model) was developed to integrate Chinese energy systems with water resources, to project the future water demand, and to evaluate the impacts of water constraints on water demand and generation portfolio of power sector out to the year 2050. We find that water fee has limit impact in the short-term, while significant impact in the long-run for power sector, in terms of the water demand and power generation portfolio.

\section{Introduction}

China is currently facing a series of energy and water problems. The energy and water issues have restricted the improvement of living standard and the development of social economy. To ease these pressures, Chinese government has set a list of targets on energy and water use, and proposed a series of "energy saving and carbon mitigating" and "water saving and pollution controlling" measures ${ }^{[1-2]}$. Up to now, a number of studies have been carried out to evaluate the connection of energy and water demand ${ }^{[3-5]}$. To date, few studies have considered the water demand of future power sector at China's national level. Additionally, the evaluations of impacts of water constraint on China's power sector are rare. In this paper, a partial equilibrium model (CEMES model) was developed to integrate China's energy and water system, to evaluate the impacts of water constraints on water demand and generation portfolio. It should give some insights for China's sustainable development.

The rest of the paper is organized as follows: Section 2 is a methodological section; Section 3 lists the results of the model, including the impacts of water constraints on the water demand and power generation portfolio. The last section provides the conclusion for our work.

\section{Methodology}

\section{Water demand estimation}

Power sector is the main user in China. The water demand is mainly affected by the activity level, power generation type, and the cooling type. In this model, we consider the following technologies: coal-, oil-, gas-fired plants, nuclear, NGCC, IGCC, PV, wind, biomass and other renewable power plants. The demand is shown in Eq. (1).

$$
W W_{E L C, t}=E l c \times \sum_{\phi}\left(\gamma_{\phi} \times \theta_{\phi, \varepsilon} \times w c_{E l c, t, \phi}\right)
$$

Where $W W_{E L C, t}$ : The water demand in power sector in year $\mathrm{t}\left(\mathrm{m}^{3}\right) ; E l c$ : The domestic electricity demand (Gwh); $\gamma_{\phi}$ : The share of power generation technology $\phi ; \theta_{\phi, \varepsilon}$ : The share of cooling type $\varepsilon$ in power generation technology $\phi ; w c_{E l, t, \phi}$ : The water coefficient of power generation technology $\phi$ in year $\mathrm{t}\left(\mathrm{m}^{3} / \mathrm{Mwh}\right)$, namely the water demand to produce one unit of electricity; $\varepsilon$ : The type of cooling type, such as open-loop cooling, close-loop cooling, etc; $\phi$ : The type of power generation technology; $t$ enotes Time.

Primary energy sector is also an important water user in China. The water demand in this sector is also related to the activity level and water coefficient. The water demand is shown in Eq. (2).

$$
W W_{U P S, t}=\sum_{\varphi} P_{t, \varphi} \times w c_{U P S, t, \varphi}
$$


Where $W W_{U P S, t}$ : The water demand in primary energy sector in year $\mathrm{t}\left(\mathrm{m}^{3}\right) ; P_{t, \varphi}$ : The activity level of primary energy sector $\varphi$ in year t (tce); $w c_{U P S, t, \varphi}$ : The water coefficient in primary energy sector $\varphi$ in year $\mathrm{t}\left(\mathrm{m}^{3} / \mathrm{tce}\right) ; \varphi$ : The type of technology, such as coal mining and washing.

\section{Energy-Water linkage}

Figure 1 illustrates the linkage between energy system and water system in the model. In the water module, the supply side includes the conventional water and non-conventional water; the demand side include the agriculture, industry, residential, ecological, and energy related water demand.

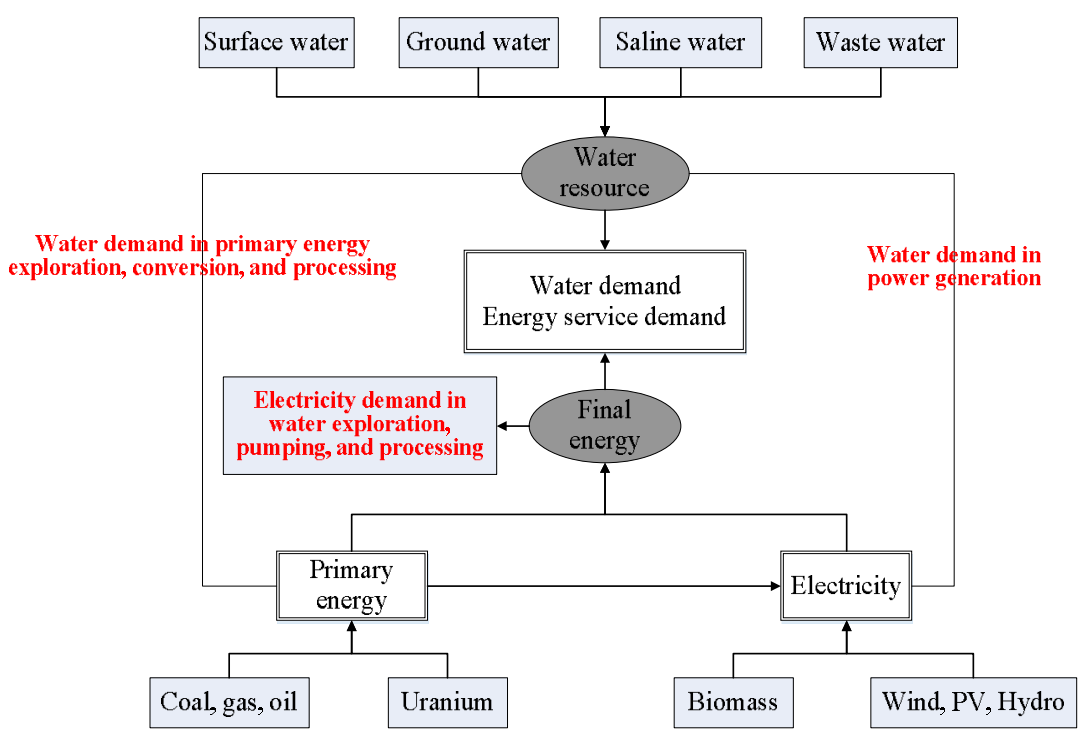

Figure 1 Representation of the energy-water linkage in CEMES model

Due to the detailed description of technologies in power sector, and due to the wide variation in the water demands of different power generation technologies, we use a relatively detailed representation of water module. For a specific technology, three types of cooling systems - open-loop cooling, close-loop cooling, dry cooling, and sea water cooling - are considered. We made some assumptions about the shares of four types of cooling technologies in the model, based on the average water coefficients, and the current power generation and water use.

\section{Assumptions and scenario definition}

The basic assumptions are as follows: with the consideration of "selective two-child policy", the China's population will reach a peak in 2030, about 1.47 billion, and the urbanization rate will be about $62.5 \%$; then the population will steadily decrease to 1.38 billion in 2050, and the urbanization rate will be $75.0 \%$. The average annual GDP growth rates are assumed to increase by $7.5 \%, 6.0 \%$, $4.5 \%$, and 3.5\% during the period 2010-2020, 2020-2030, 2030-2040, and 2040-2050.

Three scenarios were developed and investigated in this paper, include a Reference scenario (RES) and two water fee (WF) scenarios. Under the RES scenario, we considered the national energy and water development planning plans and objectives, such as the $12^{\text {th }} F Y P$, the $12^{\text {th }}$ FYP of Energy Development, and the $12^{\text {th }}$ FYP of Water Resources Development, etc. Under the WF scenarios, the water fee is modeled as an additional cost of $0.5 \$ / \mathrm{m}^{3}$ in WF1 scenario and $1.0 \$ / \mathrm{m}^{3}$ in WF2 scenario.

\section{Result}

\section{Impact of water constraints on water demand in power sector}

Figure 2 presents the power sector's water demand under three scenarios during 2010-2050. Under the RES scenario, the electricity demand is expected to increase from 4,180 Twh in 2010 to 12,450 Twh in 2050, and the water demand in power sector is estimated to increase from 43.2 billion $\mathrm{m}^{3}$ to 93.5 billion $\mathrm{m}^{3}$ during the same time period. It is observed that coal- and nuclear-based power plants 
are two main water users in power sector, followed by other generation types, such as gas-, oil-based, and renewable power plants. The coal-fired power plants use $85.0 \%$ of water, $68.0 \%$ in $2020,60.0 \%$ in 2030, and $52.0 \%$ in 2050, and nuclear power plants account for $8.0 \%$ in $2010,18.0 \%$ in 2020 , $25.2 \%$ in 2030, and $35.4 \%$ in 2050 . As the coal- and nuclear-based power generation are two of the most water-intensive technologies, the introduction of water fee will result in an increased production cost of water withdrawal based power generation technologies (thermal, nuclear, and biomass, etc.), which can lead to a change in power generation structure and a reduction of water demand.

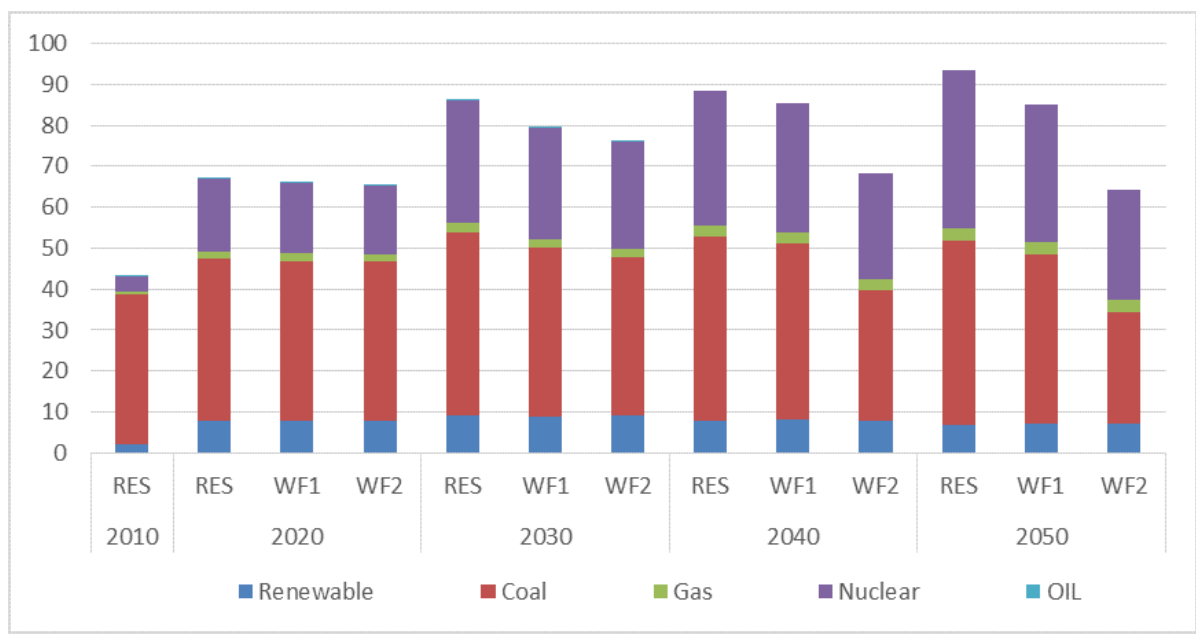

Figure 2 The water demand in power sector (billion $\mathrm{m}^{3}$ )

It is observed that the higher water fee, the more significant effect on water saving in power sector. Figure 2 shows that the water demand in China's power sector will increase from 43.2 billion $\mathrm{m}^{3}$ in 2010 to 80.3 billion $\mathrm{m}^{3}$ (WF1), and 76.5 billion $\mathrm{m}^{3}$ (WF2) in 2030, to 85.2 billion $\mathrm{m}^{3}$ (WF1), and 68.4 billion $\mathrm{m}^{3}$ (WF2) in 2050. During 2010-2020, the water saving is limited because of the long lifetime period (>30 years) of power generation plants, the generation structure will not change a lot in the short term. But since 2030, the water demand in power sector is obviously lower in water fee scenarios than the reference scenario. Under the WF1 scenario, the coal-fired power plants use 56.8\% of water in 2030, and $45.2 \%$ in 2050, and nuclear power plants account for $21.2 \%$ in 2030 , and $30.8 \%$ in 2050. Under the WF2 scenario, the coal-fired power plants use $50.4 \%$ of water in 2030 , and $41.8 \%$ in 2050, and nuclear power plants account for $18.8 \%$ in 2030, and $26.8 \%$ in 2050.

\section{Impact of water constraints on generation portfolio}

Figure 3 illustrates the power generation structure under three scenarios by presenting the share of electricity generation in 2020, 2030, 2040, and 2050. Common on all three scenarios in 2020, coal-based power plants are particularly important, accounting for nearly $68.0 \%$ of the total power generation. This is the same trend of current generation structure. However, its further evolution depends on technology maturity and the price of water fee. It is observed that water fee will have significant effect on the power generation portfolios since 2030. Under the RES scenario, the share of coal-fired power generation will decrease from $78.0 \%$ in 2010 to $64.2 \%$ in 2030 , and to $60.4 \%$ in 2050; while under the water fee scenarios, the share will decrease to $63.8 \%$ (WF1) and $62.6 \%$ (WF2) in 2030 , to $56.7 \%$ (WF1) and $49.6 \%$ (WF2) in 2050. Under the reference scenario, the share of renewable power will keep increasing during 2010-2050, but the share is very low, while under the two water fee scenarios, the renewable power will account for $25.8 \%$ (WF1) and $33.0 \%$ (WF2) in 2050. Other power generation has limited change under the water fee scenarios. 


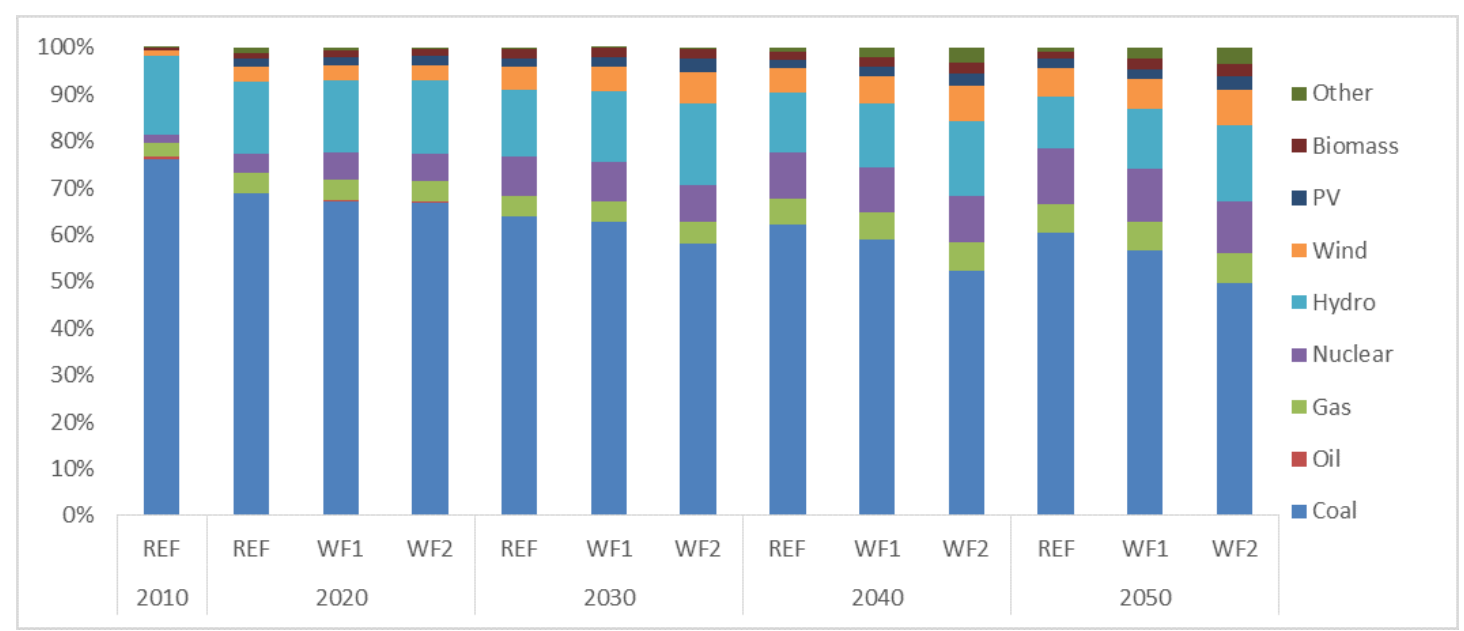

Figure 3 Comparisons of power generation portfolios among three scenarios (\%)

\section{Conclusions}

This paper projected the water demand by subsectors between 2010 and 2050, analyzed the effect of selected water fees on water demand and generation portfolio in China's power sector, by using the China CEMES model.

The water demand in power sector will keep increasing, and the water demand will concentrate in the coal-fired power and nuclear power sector. The water issue will be an important challenge to the sustainable development of China's power sector. The coal-fired plants are the dominant electricity generation technologies in all scenarios followed by hydro and nuclear power plants in the later period (2030-2050). The introduction of water fee will reduce the water demand in power sector and affect the power generation structure significantly, from high water coefficient technologies to low or zero water coefficient technologies. Their impact seems to be limited in the short term, but significant effective in the long run.

Energy and water issues are already very serious now in China. In order to have a sustainable of water and energy resources, future research should be carried out to better understand the nexus of water and energy. On the one hand, the impact of water constraint on the GHG mitigation under different environmental and economic conditions should be evaluated. On the other hand, the performance of water conservation technologies and energy saving measures should also be considered in further analyses.

\section{References}

[1] Li G., Wen Z., Du B., Chen J., 2008. An analysis of industrial water conservation potential and selection of key technologies based on the IWCPA model [J]. Resources, Conservation and Recycling 52(2008):1141-1152.

[2] General Office of the State Council, 2011. The Comprehensive Program for 12th Five-Year Plan of "Energy Saving and Emission Reduction" [R].

[3] Dubreuil A., Assoumou E., Bouckaert S., et al., 2013. Water modeling in an energy optimization framework - the water-scarce middle east context [J]. Applied energy 101(2013):268-279.

[4] Bouckaert S., Assoumou E., Selosse S., 2014. A prospective analysis of waste heat management at power plants and water conservation issues using a global TIMES model [J]. Energy 68(2014):80-91.

[5] Welsch M., Herman S., Howell M., et al., 2014. Adding value with CLEWS - Modeling the energy system and its interpendencies for Mauitius [J]. Applied Energy 113 (2014):1434-1445.

[6] Zhang Liang, 2013. The projection of water resource demand in the next 10 years. 